\title{
繰り返し学習制御を利用した アームを持つ水中ロボットの本体姿勢補償
}

\author{
○正 坂上 憲光（東海大）
}

\section{Attitude control of Underwater Vehicle-Manipulator Systems Using Iterative Learning Control}

\author{
Norimitsu SAKAGAMI, Tokai Univ.
}

\begin{abstract}
This paper presents a feedforward compensation approach for underwater vehicle manipulator systems (UVMSs) in order to realize precise and fast motion control. Iterative learning control (ILC) is used for controlling an underwater manipulator in this paper. During manipulator motion, thrust forces eliminate reaction moment acting on a vehicle. Experiments were conducted using an underwater vehicle with a 1-degree of freedom (D.O.F) manipulator. In case of non-compensation, the vehicle attitude error was up to $10 \mathrm{deg}$ after a control period. On the other hand, the feedforward compensation approach proposed in this paper could reduce the error down to $\pm 2.0 \mathrm{deg}$.
\end{abstract}

\section{1.はじめに}

一人で持ち運び可能な小型水中ロボットは，操縦や運用・ メンテナンスの容易さから海・湖沼・河川・ダムなどで広く 使われている．著者は，一人で持ち運べるサイズの小型水 中ロボットにマニピュレータを搭載することで，水中での 作業内容の拡大と効率化を目指している。マニピュレータ のサイズが同じとした場合，ロボット全体が小型なほど揮 搬やメンテナンスも容易になる。ただしその際，マニピュ レー夕動作時の流体力から生じる本体への影響, 浮心・重心 の位置関係，操縦装置など考えなければならない問題は増 える。そ問題の一つの解決法として本研究では，ロボッ トが浮遊した状態でアームを動かす場合でも，その反力を スラス夕推力によってキャンセルし，ロボット姿勢を維持 する方法を提案する。

従来の小型水中ロボットのマニピュレータ作業の多くが 海底や湖底に着底した状態で行なわれる場合が多いのに対 して，本研究では水中ロボットが浮游した 3 次元空間中で も水中作業ができるようにする事を目指している。

\section{2. 姿勢補償の概要}

本原稿で提案する補償法の概略は次の通りである。まず， 水中ロボット (図 1) のマニピュレータには繰り返し学習 制御 [1] を適用し，その時にロボット本体に加わるトルク を計測しておく。また，あらかじめスラス夕推力がロボッ ト本体に加わえることのできるトルクを計測しておく。 の $2 つ の$ 関係を利用して, マニピュレー夕動作時にロボッ ト本体に加わるトルクをスラス夕推力によってキャンセル し，ロボット姿勢の補償を行なう。

図 2 に以上の流れを示す。まず，水中ロボットをトルク センサに固定した状態で，マニピュレータにいくつかの典 型的な作業時の運動パターン (Motion 1,2, ․) を学習さ せる。この結果、マニピュレータのフィードフォワード制 御入力が得られる [2]. このときトルクセンサから，ロボッ 卜本体に加わるトルクも計測しておく。これらの情報は計 算機の記憶装置に保持しておく（図 2 の左上）。

続いて，スラス指令電圧とスラス夕推力によってロボッ 卜本体に加わるトルクの関係を求める（図 2 の右上）。

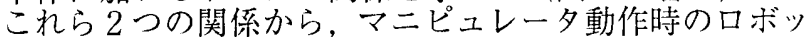
卜本体に加わるトルクをキャンセルするスラス夕指令電圧 を計算する。この指令電压をスラス㞦加えることで水中 ロボット本体の姿勢補償を本稿では実現する。

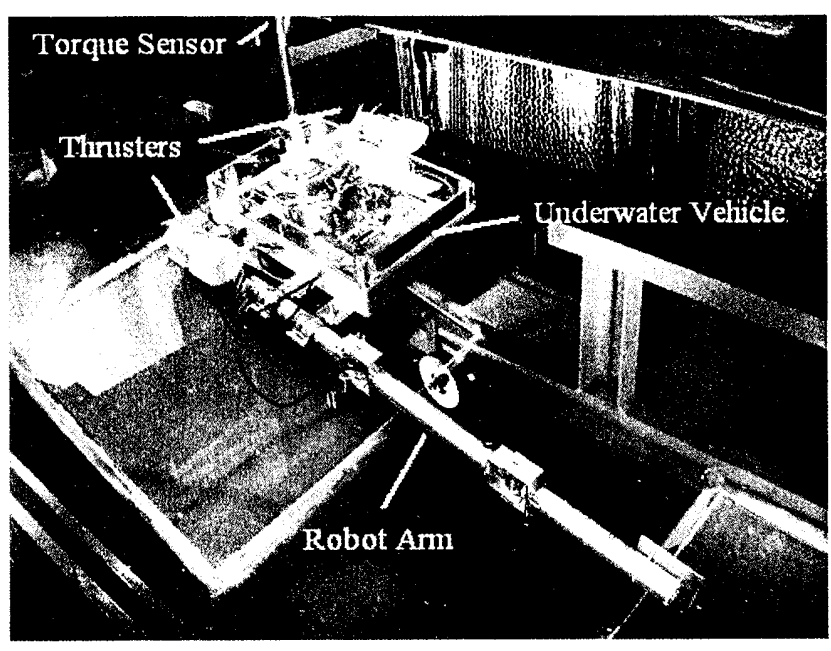

Fig.1: Underwater vehicle manipulator system

\section{3. 実験装置}

図 1 に 1 自由度アームを持つ水中ロボットを示す。こ の水中ロボットは内部に PC104 CPU メインボード，DA ボード，CNT ボードを搭載し，2つのスラス夕および 1 自由度アームのモー夕を制御するために用いる。ロボット の空中重量は $5[\mathrm{~kg}]$ であり, 水中では中性浮量を保ってい る。アームを伸ばした時の全長は約 $600[\mathrm{~mm}]$ であり，全幅 は $400[\mathrm{~mm}]$ である。表 1 に，アームおよびアームに使用 したモータのスペックを示す.

ロボットにはトルクを計測するためにトルクセンサが取 り付けられている（このトルクセンサは姿勢補償の実験時に は取り外される)。今回の実験では水槽 $(1.4 \times 2.8 \times 0.9[\mathrm{~m}])$ を用いる。

\section{4. アームの繰り返し学習制御}

まず，繰り返し学習制御によってロボットアームのフィー ドフォワード制御入力を得る。今回は目標運動パターン $q_{d}(t)$ の一つとして，運動終了時にアーム先端がロボットの正面 まで移動する軌道を選んだ。

$$
q_{d}(t)=60\left(\frac{6}{T^{5}} t^{5}-\frac{15}{T^{4}} t^{4}+\frac{10}{T^{3}} t^{3}\right)[d e g]
$$




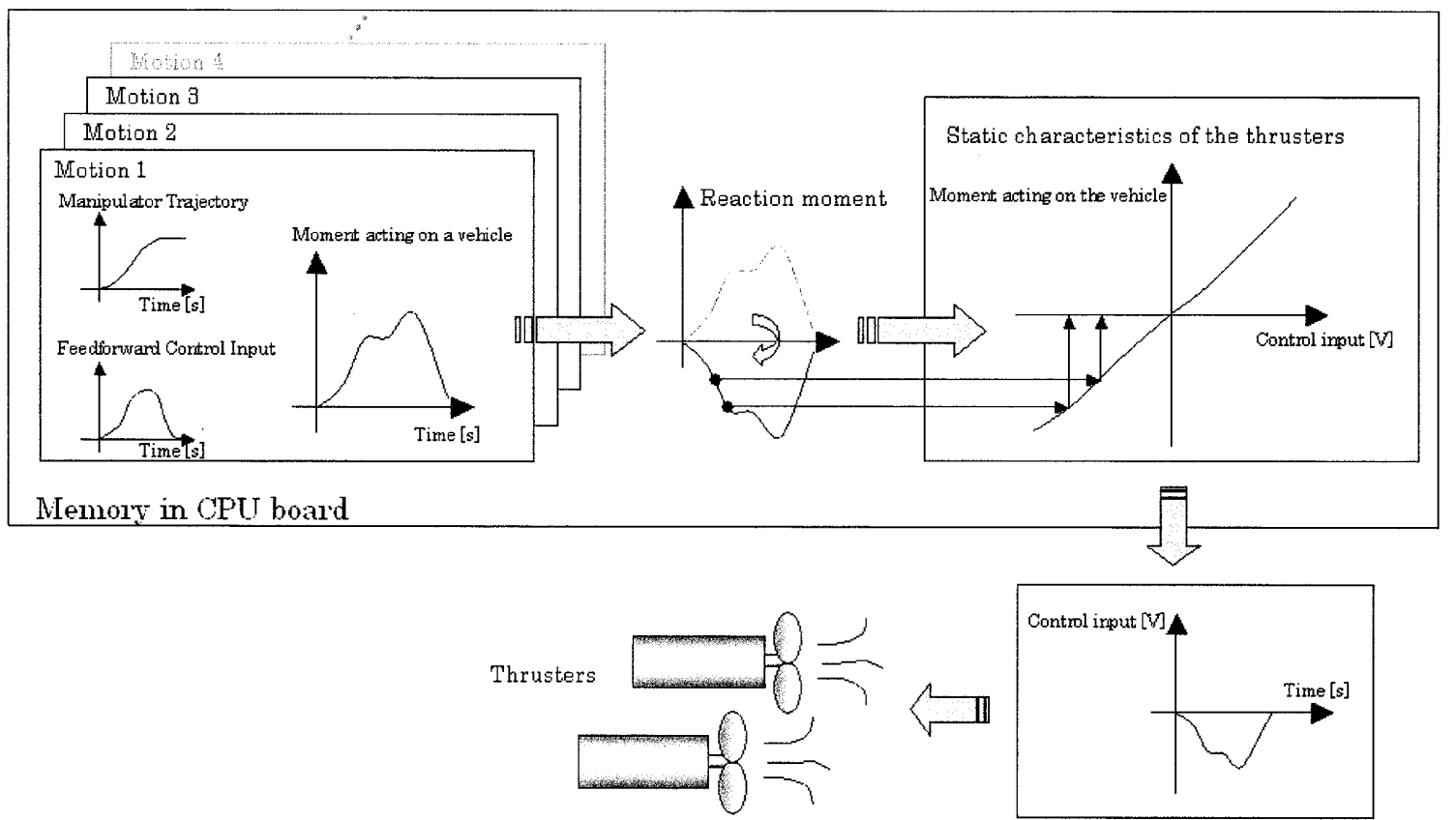

Fig.2: This figure shows the schematic of a feedforward compensation approach

Table 1: Specifications of manipulator and actuator

\begin{tabular}{|c|c|}
\hline & Link \\
\hline Link length [m] & 0.14 \\
\hline Link diameter [m] & $\phi 0.022$ \\
\hline Rated torque [N] & 0.03 \\
\hline Rated revolution [rpm] & 60 \\
\hline Resolution [Pulse/rev] & 300 \\
\hline Reduction ratio & $1: 297$ \\
\hline
\end{tabular}

$$
0 \leq t \leq 1.0[s]
$$

ここで $T$ は制御の終端時間である。軌道の時間列デー夕 は図 3 に示す.アームの初期角度 $q_{d}(0)$ はロボット本体の 前方に真っ直ぐ伸ばした状態であり，時間の経過とともに アームの先端がロボットの正面にまで動作する。

学習制御入力の修正は

$$
u_{k+1}=u_{k}+\Phi \Delta q_{k}(t)+\Psi \Delta q_{k}(t)
$$

によって与えられる。ここで $k$ は試行回数, $u$ はフィード フォワード入力パターン, $\Phi$ は学習 $\mathrm{P}$ ゲイン， $\Psi$ は学習 I ゲイン, $\Delta q\left(=q_{d}-q\right)$ は角度誤差である.今回の実験で は, アームのモータへの指令電圧をフィードフォワード入 カパターン $u$ とし $, \Phi=0.035, \Psi=0.0036$ を選んでい る。必要であればいくつかの運動パ夕ーンを同様に学習し, フィードフォワード制御入力を得ておく。

アームの角度の誤差ノルムを

$$
\frac{1}{T} \int_{0}^{T} \Delta q^{2}(t) d t
$$

と定義すると，実験ではこの誤差ノルムが試行回数が増す ごとに減少し，学習終了後には $1.0[\mathrm{deg}]$ 以下までになった。 学習の結果得られたフィードフォワード制御入力を図 4 に 示す。このとき同時に，アームの動作によつてロボット本 体に加わるトルクも計測し, 図 5 に示す結果となった。

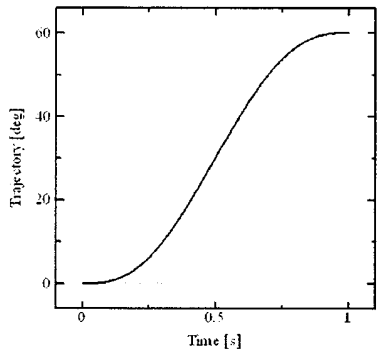

Fig.3: Trajectory for the manipulator

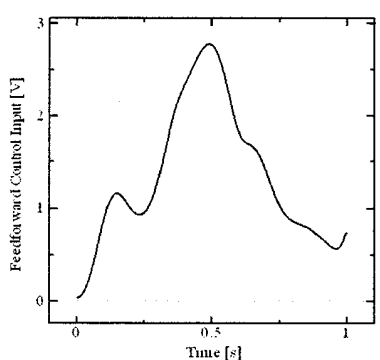

Fig.4: Feedforward control input for the manipulator

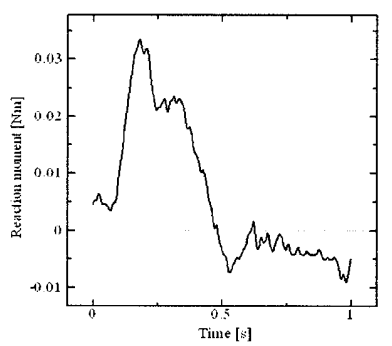

Fig.5: Moment acting on the vehicle

\section{5. スラスタ推力による本体トルクの計測}

次にスラスタへの指令電圧とスラス夕推力によってロボッ ト本体に発生するトルクの関係を求める。同じく図 1 の実 験システムを利用する。

今回は，スラス夕の指令電圧と定常的なスラス夕推力の 関係を求め, ロボットの浮遊状態での本体姿勢補償に用い る。この結果を図 6 に示す。

今回は定常的なスラス夕推力の関係を用いたが，より高 精度でより動的な運動に対応古るためには，動的なスラス 


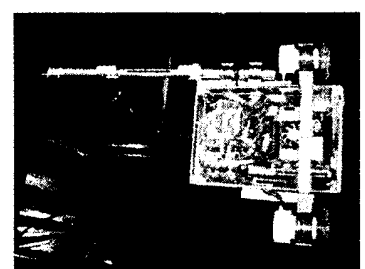

$0.00[\mathrm{~s}]$

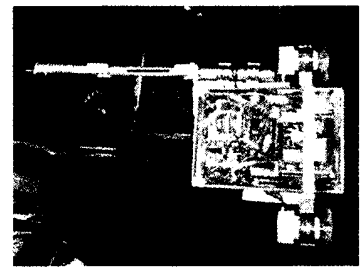

$0.00[\mathrm{~s}]$

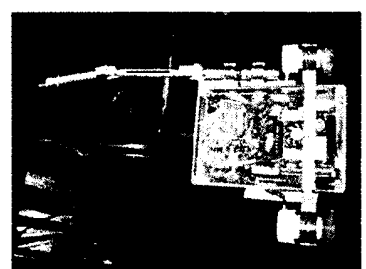

$0.33[\mathrm{~s}]$

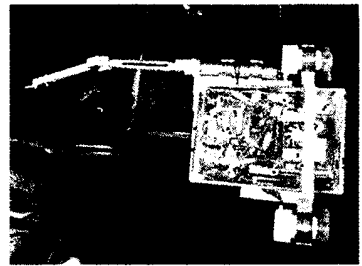

$0.33[\mathrm{~s}]$

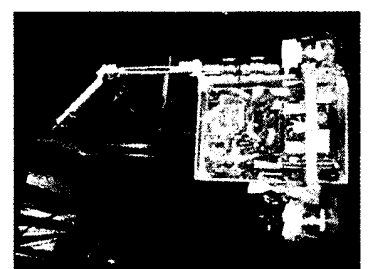

$0.66[\mathrm{~s}]$

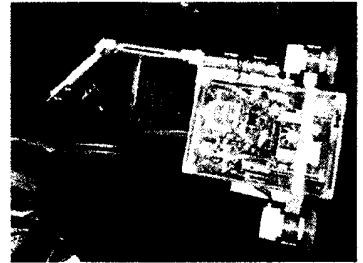

$0.66[\mathrm{~s}]$

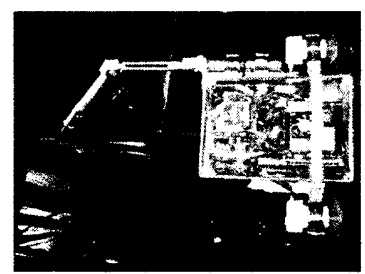

$1.00[\mathrm{~s}]$

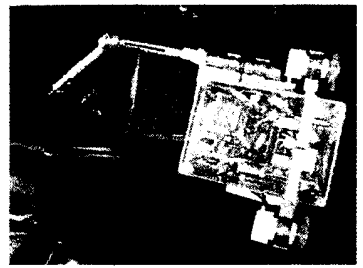

$1.00[\mathrm{~s}]$

Fig.8: Upper pictures show the result of the feedforward compensation approach. Lower pictures show the case of non-compensation.

タモデル（例えば[3]）などに基づく関係を，将来は利用す る必要があるだろう。

\section{6. ロボット本体の姿勢補償実験}

まず，計測用に取り付けられていたトルクセンサを水中 ロボット本体から取り外し，水中ロボットは自由に動くこ とができる状態で姿勢角の補償実験を行う。

アームは学習制御によって得られたフィードフォワード 入力を用いて制御される。同時に，アーム動作からロボッ 卜本体に加えられるトルク（図 5) をキャンセルできるよ うに，スラス夕指令電圧と本体へのトルクの関係（図 6) を用いてスラス多指令電圧を計算する（四 7).このスラ スタへの指令電压を用いてロボットの姿勢角を補償する。

上記の方法によって水中ロボット本体の姿勢を補償した 場合と，姿勢補償を行なわなかった場合の結果を図 8 に 載せる.図 8 の上の写真が本体の姿勢補償を行なった場合 であり，図 8 の下の写真が姿勢補償を行わなかった場合で ある。

今回の水中ロボットには姿勢角を計測するセンサを搭載 できるスペースが無かったため，この姿勢角変化は実験時 の動画を画像妈理することによって求めた。この結果を図 9 にプロットする。

図 9 から，姿勢補償を行なった場合は水中ロボットの姿 勢角の誤差は土2.0[deg] 以下に抑えられている。一方で, 姿勢補償を行なわなかった場合は，アーム動作終了時にロ

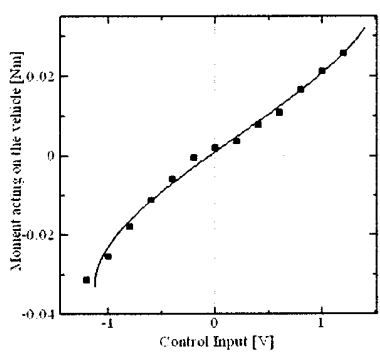

Fig.6: Static MomentVoltage (control input[V]) characteristics

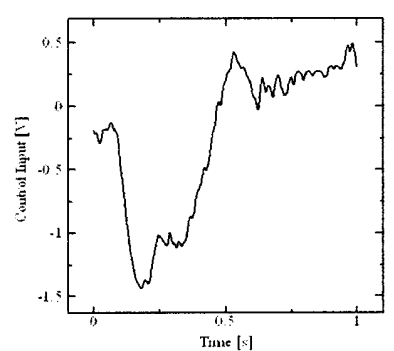

Fig.7: Feedforward control input[V]
ボット本体の姿勢角の誤差が $10[\mathrm{deg}]$ までなっている。こ の結果から，提案する方法によってアーム動作時のロボッ 卜本体の姿勢角の補償が行なわれていることがわかる。

\section{7. 今後の課題}

今後は，多くの運動パターンや多自由度アームに対して も提案する方法が有効であるか確かめる予定である。

なお，今回の実験では定常的なスラス夕推力の特性を用 いたため，ロボット本体の姿勢を補償できない場合もあり うる。今後はスラス夕の動特性も考えた上でのロボット本 体の姿勢補償を考えていく.

今回はアームのみに繰り返し学習制御を適用したが，アー ムおよびロボット本体も含めた全システムとしての繰り返 し学習制御の理論と実験も課題である.

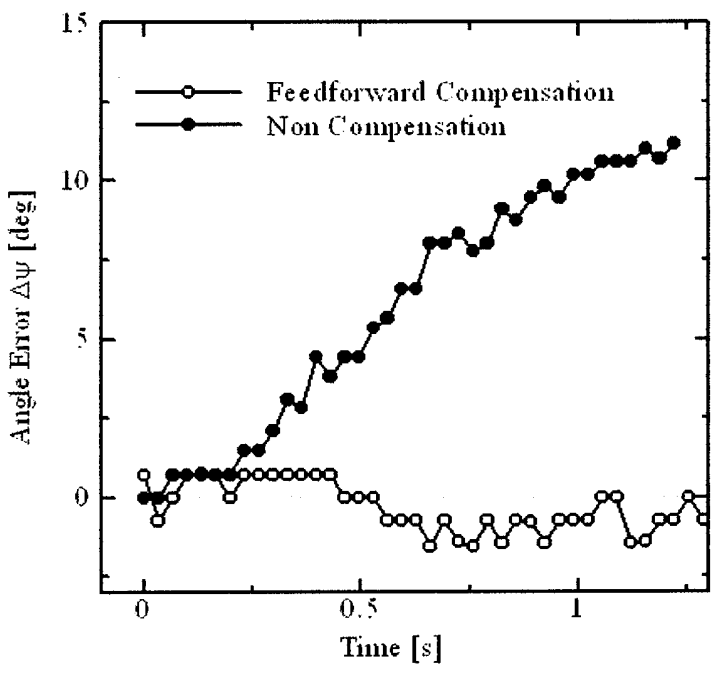

Fig.9: Angle Error $\Delta \psi[\mathrm{deg}]$ 


\section{8. おわりに}

本稿では，繰り返し学習制御を利用してアームを持つ水 中ロボットの本体姿勢角の補償を試みた。ロボットが浮遊 している状態でアームを動かす場合でも，その反力をスラ ス夕推力によってキャンセルし，ロボット姿勢を維持する 方法を提案した。

実験結果から, 水中ロボット本体の姿勢補償を行なった 場合は姿勢角の誤差が $2.0[\mathrm{deg}]$ 以下に抑えられた。一方 で，姿勢補償を行なわなかった場合には，姿勢角の誤差が $10[\mathrm{deg}]$ までとなった。 以上の結果から，本稿で提案した 方法が今回の実験条件では有効に働くことを確認した。

\section{謝辞}

本研究は, 東海大学 学部等研究教育補助金 (2009 年度) の助成を受け実施されたものである。

\section{参考文献}

[1] Arimoto S (1996) Control Theory of Nonlinear Mechanical Systems: A Passivity-based and Circuittheoretic Approach. Oxford University Press, Chapter 5, pp.157-183

[2] Sakagami N, Inoue M, Kawamura S (2003) Theoretical and Experimental Studies on Iterative Learning Control for Underwater Robots. Int. Jour. of Offshore and Polar Engineering, vol.13, no.2, pp.120-127

[3] Thor I. Fossen (1994) Guidance and Control of Ocean Vehicles. John Wiley \& Sons Ltd, pp.93-97. 